\title{
Toxicity of the brominated flame retardant tris-(2,3-dibromopropyl) isocyanurate in zebrafish (Danio rerio)
}

\author{
ZHANG Xu ${ }^{1}$, LI Juan ${ }^{1}$, CHEN MinJie ${ }^{1}$, WU Le ${ }^{2}$, ZHANG Chi ${ }^{2}$, ZHANG Jie ${ }^{1}$, ZHOU QunFang $^{3}$ \& \\ LIANG Yong ${ }^{2,3^{*}}$ \\ ${ }^{1}$ Key Laboratory of Subtropical Agriculture and Environment, Ministry of Agriculture, Huazhong Agricultural University, Wuhan 430070, China;
${ }^{2}$ School of Medicine, Jianghan University, Wuhan 430056, China;
${ }^{3}$ State Key Laboratory of Environmental Chemistry and Ecotoxicology, Research Center for Eco-environmental Sciences, Chinese Academy of
Sciences, Beijing 100085, China
}

Received July 28, 2010; accepted September 20, 2010; published online April 13, 2011

\begin{abstract}
Tris-(2,3-dibromopropyl) isocyanurate (TBC) is a heterocyclic brominated flame retardant that was recently detected in the environment in China. TBC is semi-volatile and can accumulate in the lipid of some species, but little is known about its effect on aquatic organisms. We exposed adult zebrafish to $0,0.25,1$ and $4 \mathrm{mg} / \mathrm{L}$ TBC for $28 \mathrm{~d}$ and measured the effect on survival, growth, histopathology, hormone levels, enzyme activity, and gene expression. TBC exposure had no effect on survival or growth. We observed significant damage to the liver and gill, including hepatocellular swelling and fatty degeneration in the liver as well as proliferation and edema of epithelial cells in the gills. In addition, exposure to $4 \mathrm{mg} / \mathrm{L} \mathrm{TBC}$ induced proliferation of goblet cells in the intestine of both sexes, acellular areas in the testis, and thinly scattered vitellogenic granules in vitellogenic oocytes. TBC exposure had no effect on the levels of thyroid hormones, testosterone, estradiol, liver superoxide dismutase activity, malondialdehyde content, and brain cholinesterase activity. By contrast, hepatic vitellogenin and cytochrome P4501A gene expression was significantly down-regulated in both male and female zebrafish in response to TBC exposure. Our results suggest that exposure to TBC causes a variety of potential reproductive and endocrine toxic effects.
\end{abstract}

brominated flame retardants (BFRs), tris-(2,3-dibromopropyl) isocyanurate (TBC), zebrafish, endocrine disrupting effect, vitellogenin

Citation: Zhang X, Li J, Chen M J, et al. Toxicity of the brominated flame retardant tris-(2,3-dibromopropyl) isocyanurate in zebrafish (Danio rerio). Chinese Sci Bull, 2011, 56: 1545-1555, doi: 10.1007/s11434-011-4471-6

Brominated flame retardants (BFRs) are added to a variety of commercial products to reduce the risk of fire damage [1]. However, a number of studies have shown that BFRs persist in the environment, can bioaccumulate, and can be transported long distances. Thus, there is reason to be concerned about their potential to cause harm to ecosystems and human health [2,3]. In addition, the concentration of the BFRs has been increasing annually in a range of organisms, including human breast milk [4-6]. This has been addressed to some extent by the ban of polybrominated diphenyl ethers (PBDEs) throughout the industrialized world [7].

*Corresponding author (email: ly76@263.net)
However, the levels of other forms of BFRs, including tetrabromobisphenol A (TBBPA), hexabromocyclododecanes (HBCD), and decabromodiphenyl ether (DBDPE) appear to be increasing in the environment $[8,9]$.

Tris-(2,3-dibromopropyl) isocyanurate (TBC) is a heterocyclic hexabrominated flame retardant. TBC is stable and has been widely used in polyolefin, polyphenyl alkenes, unsaturated polyester, synthetic rubber, and fibers [10]. In 2009, TBC was found, for the first time, in the environment in Hunan province, China [11]. High concentrations of TBC were found in river water $(2.33-163 \mathrm{ng} / \mathrm{L})$, surface sediments (85.0-6029 ng/g), soils (19.6-672 ng/g), earthworms $(9.75-78.8 \mathrm{ng} / \mathrm{g})$, and carp (12.0-646 ng/g) [11]. The annual 
production of TBC is $\sim 500 \mathrm{t}$ in China, which is slightly lower than the production of TBBPA, PBDEs, and HBCDs [12]. Although official production statistics are not available for the past decade, it is thought that the amount of TBC has increased because of the decline in PBDEs production and the rapid industrialization of China. The environmental effects of TBC are of some concern, particularly in light of recent evidence that TBC is persistent and can bioaccumulate [11]. Preliminary in vitro toxicological evidence suggests that TBC is not toxic to HepG2 cells [11]. However, nothing is known about the effects of TBC in vivo.

Our objective was to evaluate the potential aquatic toxicity of TBC. We exposed adult zebrafish (Danio rerio) to a high, medium, and low dose of TBC for $28 \mathrm{~d}$ and evaluated the effect on tissue pathology, hormone levels and enzyme activity.

\section{Material and methods}

\subsection{Chemicals}

We purchased tris-(2,3-dibromopropyl) isocyanurate (TBC, 97\% purity) from Sigma-Aldrich (St Louis, MO, USA). Stock solutions (1000 and $4000 \mathrm{mg} / \mathrm{L}$ ) were prepared by dissolving TBC in dimethyl sulfoxide (DMSO). All other chemicals were of analytical grade.

\subsection{Zebrafish and exposure experiment}

We obtained zebrafish (wild-type, AB strain) from the Institute of Hydrobiology, Chinese Academy of Sciences. The fish were reared following the procedures of Westerfield [13]. In brief, the fish were held in fresh water at $26 \pm 1.5^{\circ} \mathrm{C}$ under a 12 h-light: 12 h-dark photoperiod and fed fresh $\mathrm{Ar}$ temia nauplii twice daily.

Prior to the experiment, the adult zebrafish (14 weeksold) were divided into 4 groups: control (DMSO), low dose TBC $(0.25 \mathrm{mg} / \mathrm{L})$, medium dose TBC $(1 \mathrm{mg} / \mathrm{L})$, and high dose TBC (4 mg/L). Each group was stocked into triplicate glass tanks ( $6 \mathrm{~L}$, sexes held separately, $N=6$ tanks/group, 10 males/10 females per tank) containing $4 \mathrm{~L}$ filtered water for $7 \mathrm{~d}$. We measured the body weight and length of each fish (females: $0.35 \pm 0.01 \mathrm{~g}, 2.18 \pm 0.02 \mathrm{~cm}$; males: $0.33 \pm 0.01 \mathrm{~g}$, $2.19 \pm 0.01 \mathrm{~cm})$. Following acclimation, the fish were exposed to the appropriate concentration of TBC for a period of $28 \mathrm{~d}$. The final concentration of DMSO was less than $0.1 \%$. Half of the exposure solution in each tank was replaced daily. At the end of the exposure period, all fish were sacrificed using $0.01 \%$ MS-222 and their body weight and length were recorded.

\subsection{Histology}

We removed the gill, liver, intestine, and gonads from both sexes for histological examination. The tissues were fixed in paraformaldehyde solution $(4 \%$, w/v) for $24 \mathrm{~h}$, dehydrated using an ethanol gradient, embedded into paraffin wax, and sectioned at $3 \mu \mathrm{m}$. The sections were stained with haematoxylin and eosin (H\&E) and examined under a lightmicroscope. We counted the number of hepatocytes and oocytes within the field of view and noted their developmental stage (cortical alveolus (Coc), vitellogenic oocyte (Voc)).

\subsection{Hormone assays}

The fish were homogenized in $1.2 \mathrm{~mL}$ ice-cold phosphatebuffered saline $(0.01 \mathrm{~mol} / \mathrm{L} \mathrm{PBS}, \mathrm{pH}$ 7.2) and the whole body homogenate was centrifuged at $13000 \times g$ for $15 \mathrm{~min}$ at $4^{\circ} \mathrm{C}$. The supernatant was removed and the hormones levels were immediately quantified using an Abbott AXSYM immunochemical automated analyzer, using the following kits: AxSYM free triiodothyronine (FT3), AxSYM free thyroxine (FT4), AxSYM Estradiol, and AxSYM Testosterone (Abbott Laboratories, Abbott Park, IL, USA), in accordance with the manufacturer's instructions.

\subsection{Quantification of SOD and CHE activity and MDA content}

The liver and brain were removed at the end of the exposure period and immediately stored at $-80^{\circ} \mathrm{C}$ until analysis. The liver and brain samples from 5 individuals in each group were homogenized individually in $50 \mu \mathrm{L}$ of PBS $(0.1$ $\mathrm{mol} / \mathrm{L}, \mathrm{pH} 7.2$ ), then centrifuged at $13000 \times \mathrm{g}$ for $10 \mathrm{~min}$ at $4^{\circ} \mathrm{C}$. The supernatant was saved for the measurement of SOD and CHE activity (U/mg protein) and MDA content (nmol/mg) protein using reagent kits from Nanjing Jian Cheng Bioengineering Institute (Nanjing, China). The total protein concentration of each sample was determined using the Bradford assay (Bio-Rad, Hercules, CA, USA).

\subsection{RNA extraction and quantitative real-time PCR assay}

We prepared total RNA from the homogenized zebrafish liver using Trizol reagent (Invitrogen, Carlsbad, CA, USA) according to the manufacturer's instructions. The purified total RNA was measured at 260 and $280 \mathrm{~nm}$ using a UV-spectrophotometer (BioPhotometer plus, Eppendorf, Germany). The quality and integrity of the total RNA was verified using the ratio of absorbance at 260/280 $\mathrm{nm}$ and by electrophoresis on a $1 \%$ agarose formaldehyde gel.

The cDNA was synthesized from $2 \mu \mathrm{g}$ total RNA using M-MLV reverse transcriptase (Promega, Madison, WI, USA) according to the manufacturer's instructions. We quantified CYP1A and VTG mRNA expression using the following primers: 5'-AGGCGAGAAGGTGTTGGTT-3' (forward) and 5'-CAGCATTTCTCCTGGCATC-3' (reverse) for CYP1A and 5'-AGCTGCTGAGAGGCTTGTTA- 3' 
(forward) and 5'-GTCCAGGATTTCCCTCAGT-3' (reverse) for VTG. The primers were designed using Primer Premier 5.0 (Premier, Palo Alto, USA) to amplify a 137 base-pair (bp) fragment of the CYP1A gene and a 95-bp fragment of the VTG gene.

Each PCR reaction mixture (total volume $20 \mu \mathrm{L}$ ) contained $1 \mu \mathrm{L}$ of cDNA template, $0.1 \mu \mathrm{mol} / \mathrm{L}$ each primer, $7 \mu \mathrm{L}$ of Milli-Q water, and $10 \mu \mathrm{L}$ of $2 \times$ SYBR QPCR Master Mix (Toyobo, Osaka, JAPAN). The thermal cycling program consisted of a denaturing step $\left(94^{\circ} \mathrm{C}, 5 \mathrm{~min}\right)$ followed by 45 cycles of denaturation $\left(94^{\circ} \mathrm{C}\right.$ for $\left.20 \mathrm{~s}\right)$, annealing $\left(55^{\circ} \mathrm{C}\right.$ for $20 \mathrm{~s})$, and extension $\left(72^{\circ} \mathrm{C}\right.$ for $\left.40 \mathrm{~s}\right)$ in a PTC-200 thermal cycler equipped with a $\mathrm{Chr} 4$ real-time fluorescence detector (MJ Research, Watertown, MA, USA). We measured the gene expression levels in 7 replicates for each treatment group. We used $\beta$-actin as an internal standard, using the following primers: 5'-CAACAGAGAGAAGATGACACAGATCA-3' (forward) and 5'-GTCACACCATCACCAGAGTCCATCAC-3' (reverse). The cycle threshold (CT) value was obtained using Opticon Monitor 3.0. The target gene expression level was normalized to $\beta$-actin. The change in expression levels was analyzed using the $2^{-\Delta \Delta C T}$ method [14].

\subsection{Statistical analyses}

We used one-way analysis of variance (ANOVA) and Tukey's multiple range tests to compare between the control and treatment groups. A $P$ value of $\leqslant 0.05$ was considered significant. All results are presented as means \pm SEM. All analyses were performed in Spss 13.0 and Origin 7.5.

\section{Results}

\subsection{Mortality and growth}

There were no differences in mortality among the different groups. The mortality rate was $3.3 \%, 3.3 \%, 6.6 \%$ and $3.3 \%$ in the control, low, medium, and high dose treatment groups, respectively. There was also no difference in body weight (male: $0.41 \pm 0.01 \mathrm{~g}$; female: $0.42 \pm 0.02 \mathrm{~g}$ ) and length (male: $2.32 \pm 0.03 \mathrm{~cm}$; female: $2.30 \pm 0.03 \mathrm{~cm}$ ) between the control and the high dose treatment group, suggesting that TBC has no effect on fish growth (data not shown).

\subsection{Histopathology}

TBC exposure caused damage to the liver, gill, and intestine. However, there was no marked difference in the pathological changes between male and female zebrafish.

The hepatic lobules were clearly identified as normal in the control fish (Figure 1(a)). However, the number of hepatocyte nuclei was significantly lower in the low dose treatment group (Figure 1(b)). After $28 \mathrm{~d}$ exposure to
$4 \mathrm{mg} / \mathrm{L}$ TBC, the most significant change was vacuolization (Figure 1(c)).

Exposure to TBC caused damage to the gill primary lamella (Figure 1(e) and (f)), characterized by proliferation and edema of epithelial cells, and amalgamation of secondary gill lamella. The effects of TBC were dose-dependent, with significantly greater damage occurring at the higher concentrations. In contrast to the control (Figure $1(\mathrm{~g})$ ) group, we observed proliferation of goblet cells in the intestine of fish that were exposed to $4 \mathrm{mg} / \mathrm{L} \mathrm{TBC}$ (Figure 1(i)).

There were no obvious histological alternations in the testis of the TBC treated groups. We identified all stages of spermatogenetic cells, including spermatogonia, spermatocytes, and spermatids $(800 \times$, data not shown). However, we did note the presence of large acellular areas in the testis of fish that were exposed to $4 \mathrm{mg} / \mathrm{L}$ TBC, suggesting a decrease in the number of spermatids (Figure 2(c)).

The vitellogenic granules were thinly scattered within the Voc in the high dose group relative to the control. The Voc: Coc ratio was $1.58,1.50$ and 1.06 in the control and low and high treatment groups, respectively.

\subsection{Thyroid hormones and sex steroid levels}

TBC had no effect on the growth of zebrafish under the conditions we tested. Similarly, exposure to TBC had no effect on the levels of FT3 and FT4 in both genders (Figure 3(a) and (b)). We also found no difference in the levels of testosterone and estradiol in the whole body homogenates of fish (both sexes) that were exposed to TBC relative to the control group (Figure 3(c) and (d)).

\subsection{SOD and CHE activity and MDA content}

Exposure to TBC had no effect on SOD activity in the male fish. Conversely, there was an apparent increase in SOD activity in female fish that were exposed to $1 \mathrm{mg} / \mathrm{L} \mathrm{TBC}$ (Figure 4(a)). However, this effect was not observed in the females exposed to $4 \mathrm{mg} / \mathrm{L}$ TBC. TBC exposure had no effect on liver MDA content in both sexes (Figure 4(b)). Similarly, TBC exposure had no effect on CHE activity in the brain of zebrafish (Figure 4(c)).

\section{$2.5 \quad C Y P 1 A$ and $V T G$ gene expression}

Expression of the CYPIA gene in the liver was significantly inhibited by TBC exposure (Figure 5(a)). Compared with the control group, the expression of $C Y P I A$ was 1.26, 3.04 and 5.48 times lower in male fish that were exposed to $0.25,1$, and $4 \mathrm{mg} / \mathrm{L}$ TBC, respectively. In the female fish, CYPIA expression was significantly down-regulated by $12.71,9.18$, and 6.33 fold, in the low, medium, and high dose TBC treated groups, respectively, compared with control group.

TBC exposure also had a significant effect on $V T G$ gene expression in the liver (Figure 5(b)). In the male fish, $V T G$ 

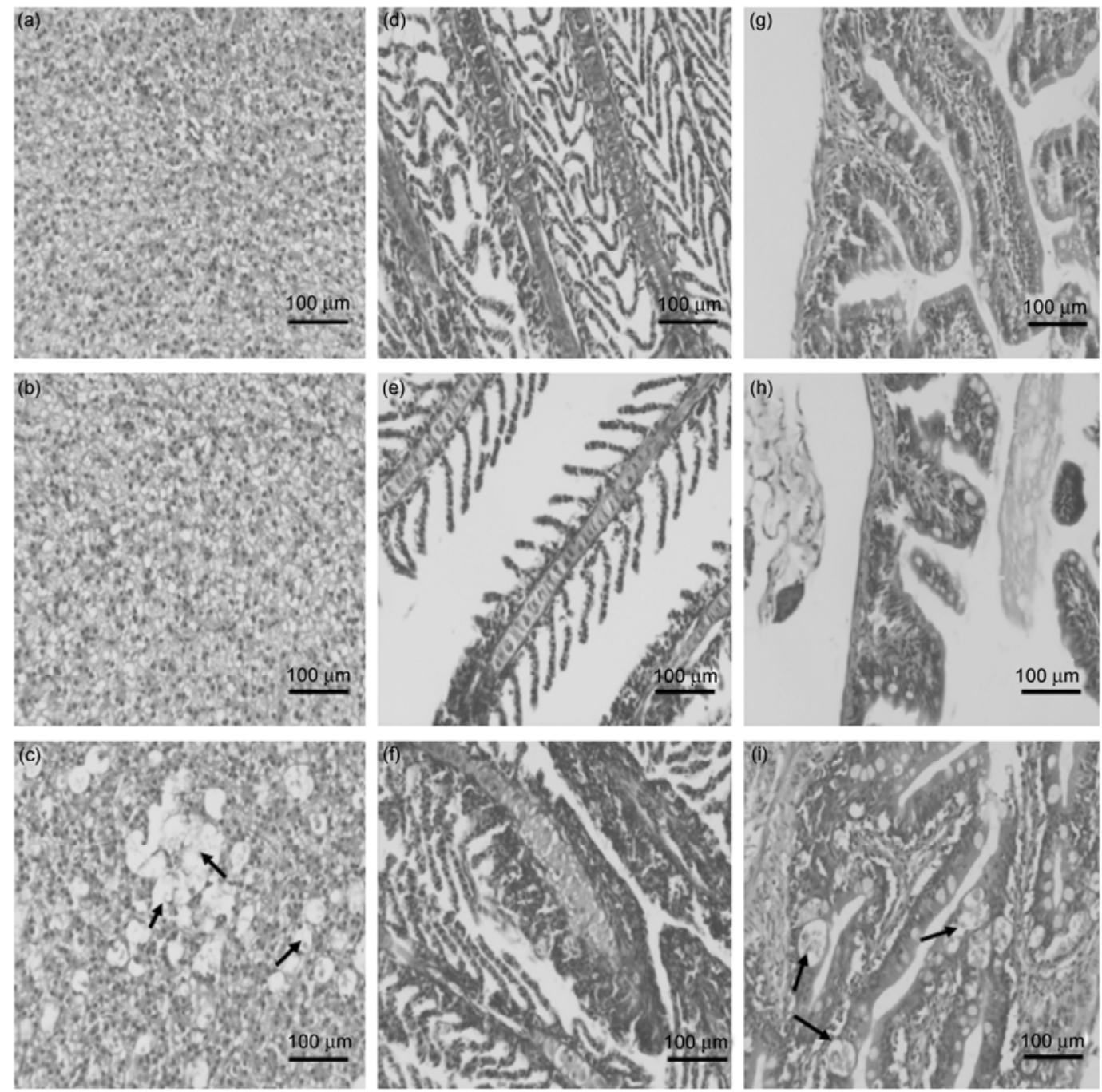

Figure 1 Light micrographs of liver, gill, and intestine from adult zebrafish exposed to TBC. (a) Liver, control; (b) liver, $0.25 \mathrm{mg} / \mathrm{L}$ TBC; (c) liver, $4 \mathrm{mg} / \mathrm{L}$ TBC treated male, showing vacuolization (arrow); (d) gill, control; (e) gill, $0.25 \mathrm{mg} / \mathrm{L} \mathrm{TBC}$; (f) gill, $4 \mathrm{mg} / \mathrm{L} \mathrm{TBC;} \mathrm{(g)} \mathrm{intestine,} \mathrm{control;} \mathrm{(h)} \mathrm{intestine,} 0.25$ $\mathrm{mg} / \mathrm{L} \mathrm{TBC}$; (i) intestine, $4 \mathrm{mg} / \mathrm{L} \mathrm{TBC}$, showing proliferation of goblet cells (arrow).

expression was 1.07, 2.87 and 9.84 fold lower in the fish exposed to $0.25,1$, and $4 \mathrm{mg} / \mathrm{L}$ TBC, respectively, though the difference was only significant at the highest dose. Similarly, $V T G$ expression was $2.17,110.13$ and 20.36 fold lower in the females exposed to $0.25,1$ and $4 \mathrm{mg} / \mathrm{L} \mathrm{TBC}$ relative to the controls. The decrease was only significant at the medium and high doses.

\section{Discussion}

TBC is environmentally persistent and has a tendency to bioaccumulate [11]. Given that the aquatic environment is the ultimate sink for many pollutants, it is important to understand the likely effects of TBC on aquatic organisms. We exposed adult zebrafish to TBC for $28 \mathrm{~d}$, then measured the effect on growth, mortality, hormone levels, and gene expression. To our knowledge these are the first data describing the effects of $\mathrm{TBC}$ in vivo.
TBC did not appear to have a significant effect on the overall health and somatic fitness of zebrafish in our study. However, TBC is accumulated in lipid-rich organs, such as the brain, liver, intestine, and fat of common carp [11]. Given this, we evaluated the toxicity of TBC in the gill, liver, intestine, and gonads. The gill is the primary gas exchange organ in teleosts and is also a direct target for water-borne pollutants [15]. For example, PBDEs are absorbed through the gill membranes and BDE47 causes apoptosis in the gill epithelial cells of rainbow trout $[16,17]$. Our results suggest that TBC exposure causes the proliferation of epithelial cells in the gill primary lamella and amalgamation of secondary gill lamella in adult zebrafish. This differs from the effect of PBDEs, likely because of the different mode of accumulation. The liver is also an important target organ for TBC accumulation [11]. Following exposure to 4 $\mathrm{mg} / \mathrm{L} \mathrm{TBC}$, we noted the presence of large numbers of vacuoles in the liver of both male and female fish. This may have been caused by hepatic cellular swelling and fatty 

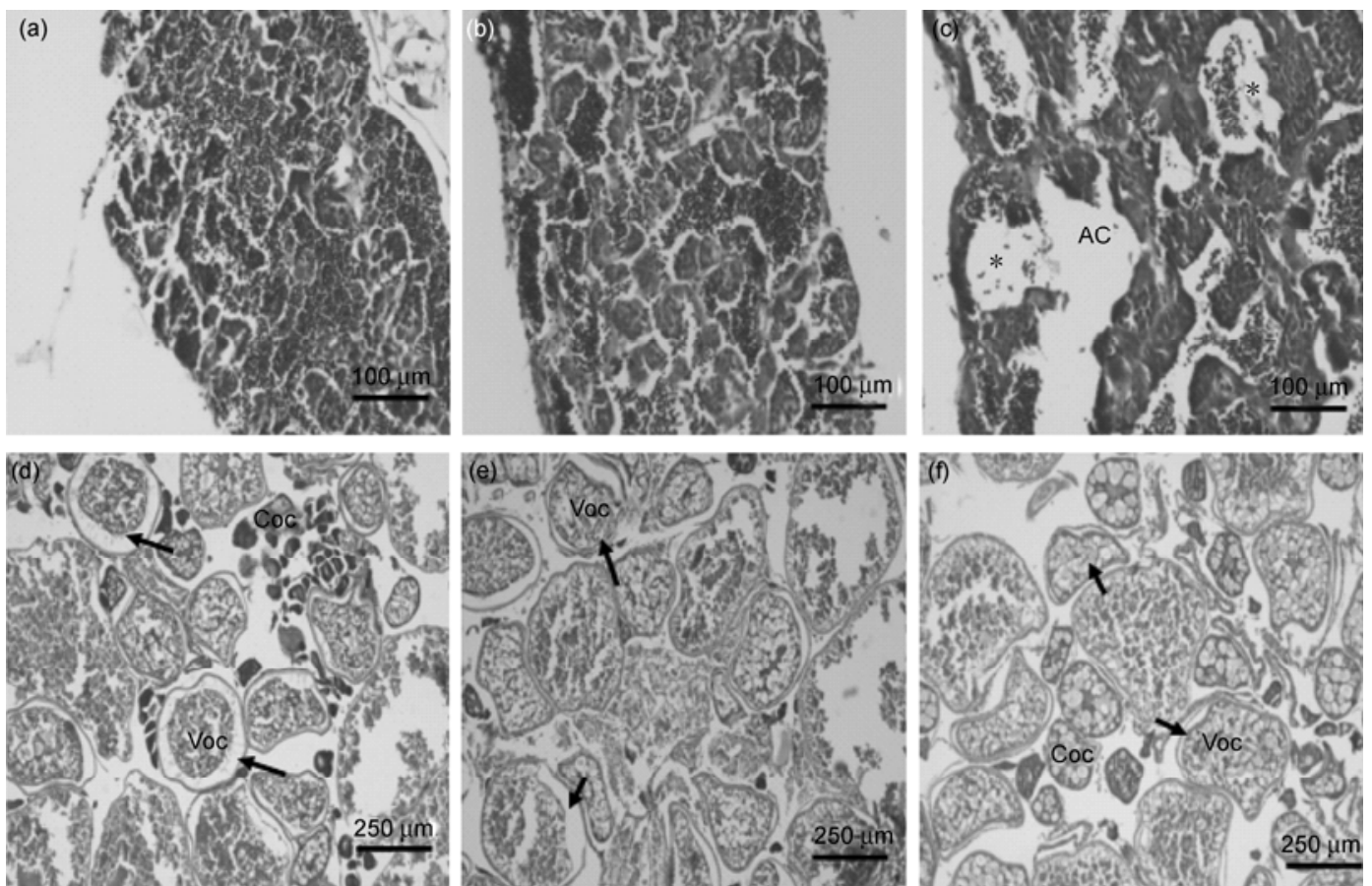

Figure 2 Light micrographs of gonads from adult zebrafish that were exposed to TBC. (a) Control male; (b) $0.25 \mathrm{mg} / \mathrm{L} \mathrm{TBC}$ treated male; (c) $4 \mathrm{mg} / \mathrm{L} \mathrm{TBC}$ treated male, showing the acellular areas (AC, asterisk); (d) ovary of control female; (e) ovary of $0.25 \mathrm{mg} / \mathrm{L}$ TBC treated female; (f) ovary of $4 \mathrm{mg} / \mathrm{L} \mathrm{TBC}$ treated female. All arrows point to the vitellogenic oocyte (Voc) stage. Coc=cortical alveolus stage.
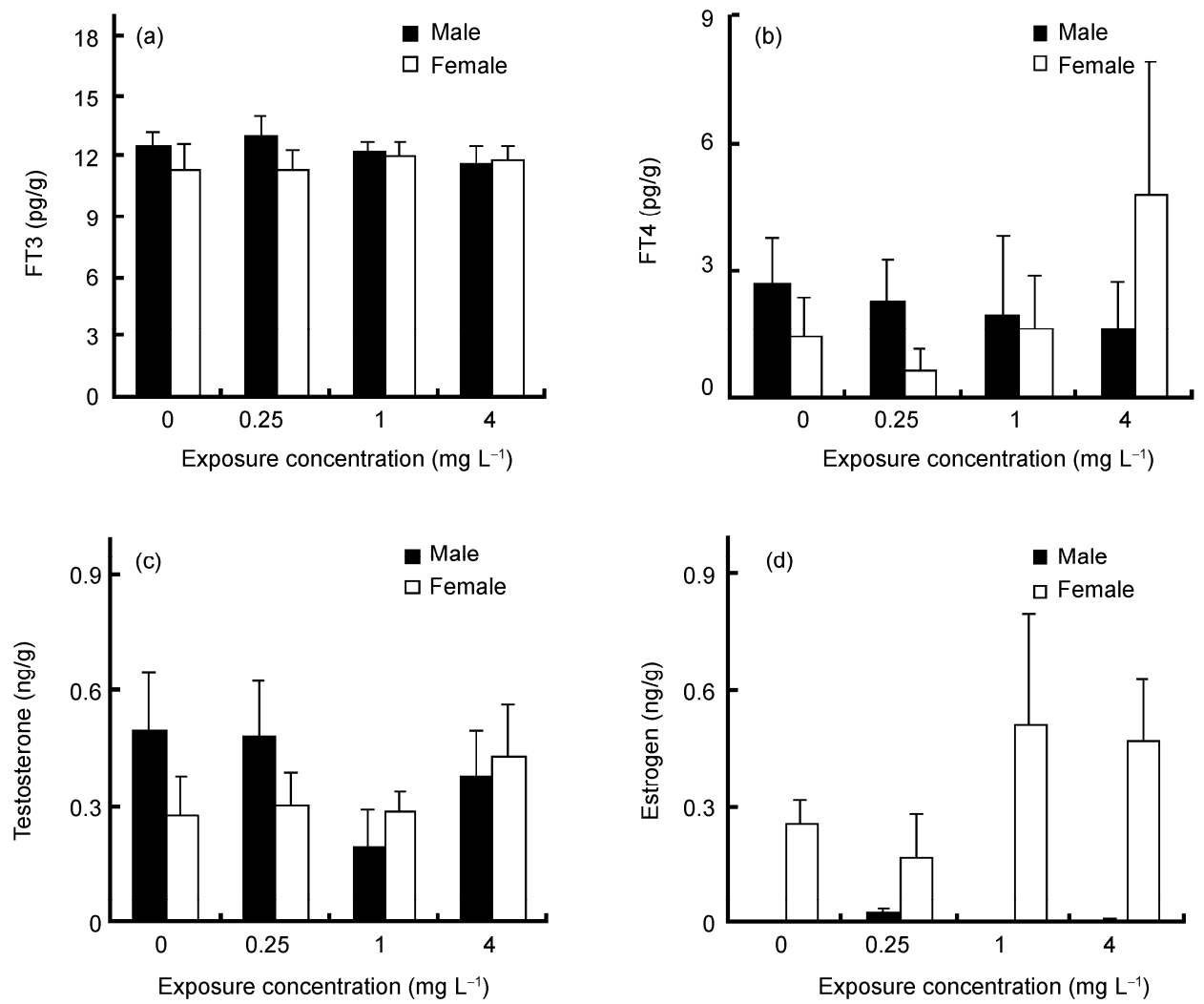

Figure 3 Effect of TBC exposure on levels of thyroid and sex hormones in adult zebrafish. Each bar represents the mean \pm SEM $(n=5)$. 

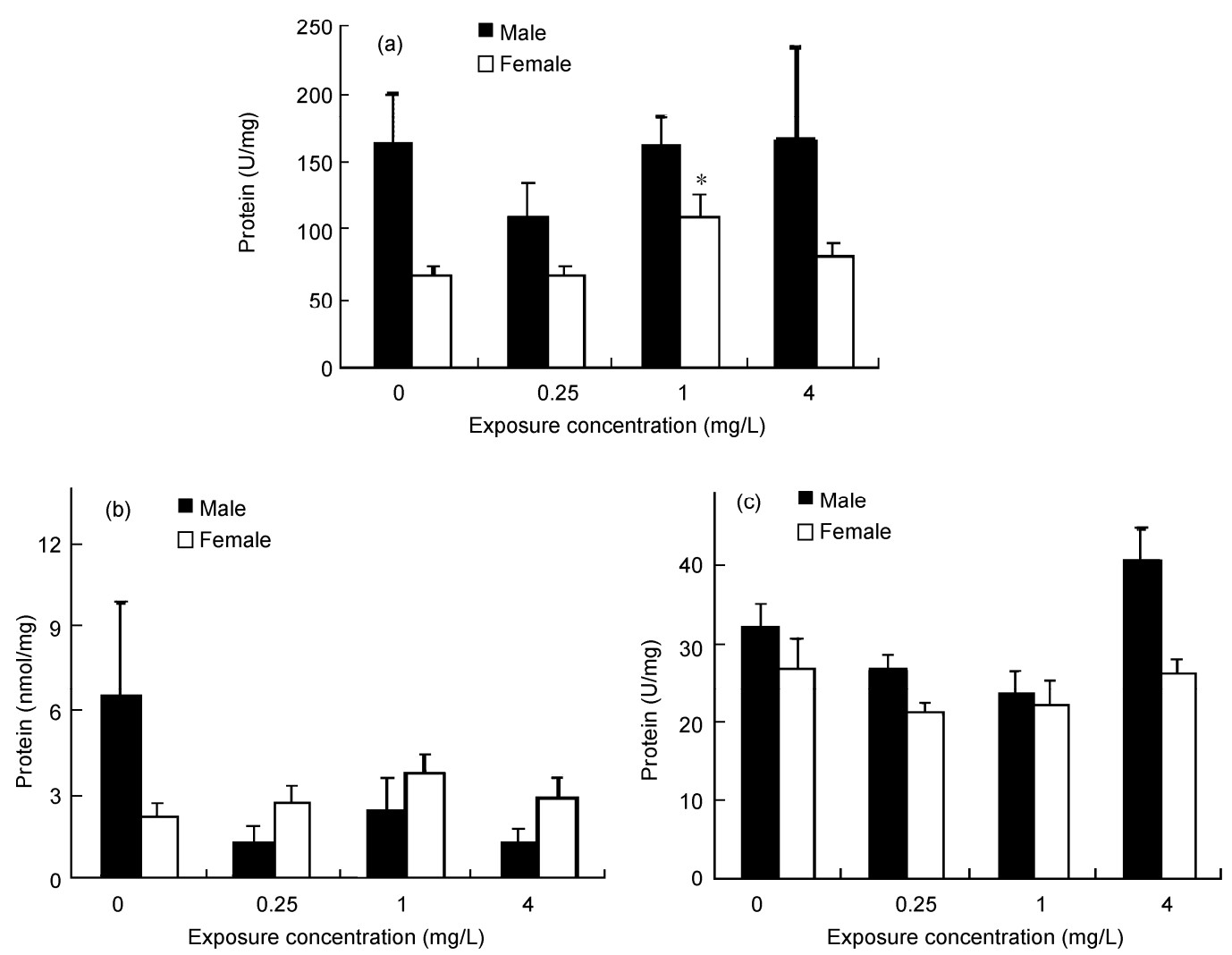

Figure 4 Effects of TBC exposure on SOD and CHE activity and MDA content in adult zebrafish. (a) Liver SOD activity; (b) Liver MDA content; (c) Brain CHE activity. Each bar represents the mean $\pm \operatorname{SEM}(n=5)$. *, Significant difference between treatment and control groups $(P<0.05)$.
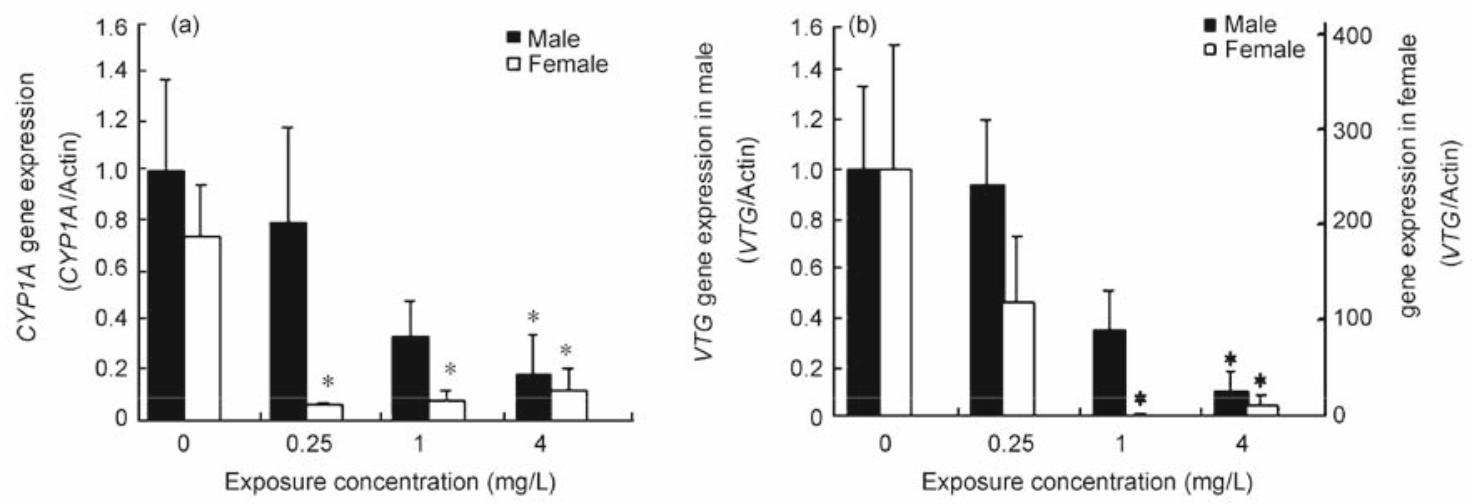

Figure 5 Effect of TBC exposure on CYPIA and VTG gene expression in the zebrafish liver. (a) CYPIA expression; (b) VTG expression. Each bar represents the mean $\pm \operatorname{SEM}(n=7)$. $*$, Significant difference between treatment and control groups $(P<0.05)$.

degeneration. This is consistent with observations of the effect of other BFRs on the liver $[18,19]$. We hypothesize that steatosis may be caused by: (1) an increase in fatty acid content in the hepatocytes; (2) over-synthesis of triglycercides; and (3) a decrease in apolipoprotein synthesis and inhibition of fat export.

The oxidative stress response plays an essential role in metabolizing toxicants and protecting hepatocytes in the liver [20]. Vertebrates, including teleosts, attempt to reduce the damage from oxidative stress using an antioxidant defense system [21]. Based on histological analysis, TBC exposure caused significant damage to the hepatocytes. However, SOD and MDA were unchanged in the liver, suggesting that there was no increase in free radicals or lipid 
peroxidation. Taking together, these observations suggest that zebrafish cannot easily metabolize TBC. This is consistent with previous reports showing that TBC has a tendency to bioaccumulate in certain species, and likely explains the irreversible hepatocyte damage in zebrafish.

Other BFRs, such as PBDE47, inhibit the activity of cholinesterase (CHE) at low doses in teleosts [22]. By contrast, TBC exposure had no effect on CHE activity in zebrafish, suggesting that TBC may be not neurotoxic, at least in this species. This may explain why we did not observe any abnormal behavior in TBC treated fish. However, TBC can pass through the blood-brain barrier and accumulate in the brain [11]. Therefore additional studies are needed to rule out effects on the brain.

Because of the variation in chemical structure, BFRs are absorbed and metabolized via many different pathways $[23,24]$, resulting in a range of toxicity mechanisms. The CYP1A family of cytochrome P450s is one of the most sensitive biomarkers of exposure to contaminants and plays a major role in the biotransformation and metabolism of xenobiotics [25]. Compounds such as dioxins and polychlorinated biphenyls induce the expression of CYPIA by binding to the aryl hydrocarbon receptor (AHR), causing its translocation to the nucleus and dimerization with the AHR nuclear translocator (ARNT) [26,27]. Because TBC has only recently been detected in the environment, little is known about its toxicity and breakdown in aquatic animals. TBC did not induce the expression of CYPIA in the zebrafish liver, suggesting that the breakdown of TBC is not associated with the aryl hydrocarbon receptor signaling pathway. This may explain its tendency to bioaccumulate in certain species [11].

A number of BFRs (e.g. PBDEs, HBCDs and TBBPA) function as endocrine disruptors by affecting thyroid function and altering steroid levels in teleosts [28-30]. However, TBC exposure had no effect on levels of the FT3, FT4 in adult zebrafish, suggesting that TBC does not disrupt thyroid function.

VTG is the precursor of yolk protein vitellogenin in oviparous organisms, including teleosts. VTG is produced in the hepatocytes via a process that is mediated by estrogens. The induction of VTG in male fish plasma or liver tissue is often used as a biomarker for evaluating the estrogenic effects of pollutants [31,32]. Interestingly, TBC exposure inhibited $V T G$ gene expression in the liver of adult zebrafish. However, TBC had no effect on levels of estradiol, suggesting that the effect on vitellogenin synthesis was not mediated via the estrogen pathway. Interestingly, the ratio of Voc to Coc was lower in the ovary of TBC exposed fish, suggesting that TBC interrupts the development of oocytes. We speculate that this may have been caused by the reduced expression of VTG in the liver. Furthermore, TBC exposure affected gonad morphology. We noted the occurrence of a large acellular area in the spermary of male gonads and thinly scattered vitellogenic granules in the Voc of female zebrafish, suggesting that TBC may inhibit reproduction. Taken together, our results suggest that TBC may act as an endocrine disrupter because of its effect on VTG production. However, the transportation, metabolism, and biotransformation of TBC involve a series of complex processes. Thus, the mechanisms responsible for the endocrine disrupting effect of TBC remain unclear.

In summary, we demonstrated that subacute exposure to TBC for $28 \mathrm{~d}$ had a number of effects in adult zebrafish: (1) TBC is toxic to the liver, gill, intestine, and gonads of adult zebrafish; (2) CYPlA gene expression is significantly inhibited by TBC, suggesting that AHR pathway may not be involved in TBC metabolism in zebrafish; and (3) TBC disrupts $V T G$ expression, suggesting that $\mathrm{TBC}$ is an endocrine disruptor. Our results highlight the need to characterize the toxicity of novel heterocyclic BFRs, such as TBC, as they may present a hazard to aquatic ecosystems.

This work was supported by the National Natural Science Foundation of China (20890112 and 20907017), the National Basic Research Program of China (2009CB421605), the National High Technology R\&D Program of China (2007BAC27B01), and the State Key Laboratory of Environmental Chemistry and Ecotoxicology (KF2009-05).

1 Stapleton H M, Allen J G, Kelly S M, et al. Alternate and new brominated flame retardants detected in US house dust. Environ Sci Technol, 2008, 42: 6910-6916

2 Vallack H W, Bakker D J, Brandt I, et al. Controlling persistent organic pollutants-what next? Environ Toxicol Pharmacol, 1998, 6: 143175

3 Birnbaum L S, Staskal D F. Brominated flame retardants: Cause for concern?. Environ Health Perspect, 2004, 112: 9-17

4 Schecter A, Pavuk M, P pke O, et al. Polybrominated diphenyl ethers (PBDEs) in US mothers' milk. Environ Health Perspect, 2003, 111: 1723-1729

5 Adrian C, Andreas C G, Robin J L, et al. Hexabromocyclododecanes (HBCDs) in the environment and humans: A review. Environ Sci Technol, 2006, 40: 3679-3688

6 Polder A, Gabrielsen G W, Odland J, et al. Spatial and temporal changes of chlorinated pesticides, $\mathrm{PCBs}$, dioxins (PCDDs/PCDFs) and brominated flame retardants in human breast milk from Northern Russia. Sci Total Environ, 2008, 39: 41-54

7 Fangstrom B, Athanassiadis I, Odsjo T, et al. Temporal trends of polybrominated diphenyl ethers and hexabromocyclododecane in milk from Stockholm mothers, 1980-2004. Mol Nutr Food Res, 2008, 52: 187-193

8 Zhang X L, Luo X J, Mai B X, et al. Spatial distribution and vertical profile of polybrominated diphenyl ethers, tetrabromobisphenol A, and decabromodiphenylethane in river sediment from an industrialized region of South China. Environ Pollut, 2009, 157: 1917-1923

9 Lam J C W, Lau R K F, Murphy M B, et al. Temporal trends of hexabromocyclododecanes (HBCDs) and polybrominated diphenyl ethers (PBDEs) and detection of two novel flame retardants in marine mammals from Hong Kong, South China. Environ Sci Technol, 2009, 43: 6944-6949

10 Xiong X Y. Microencapsulated flame retardant of TBC and its implication (in Chinese). Flame Retardant Mater Technol, 1999, 3: 1-3

11 Ruan T, Wang Y W, Wang C, et al. Identification and evaluation of a novel heterocyclic brominated flame retardant tris (2,3-dibromopropyl) isocyanurate in environmental matrices near a manufacturing plant in southern China. Environ Sci Technol, 2009, 43: 3080-3086

12 Liu H H, Wang Q J, You Y R, et al. Research of synthesis of Flame Retardant of TBC (in Chinese). Flame Retard Mater Technol, 1991: 29-33 
13 Westerfield M. The Zebrafish Book: A Guide for the Laboratory Use of Zebrafish (Brachydanio rerio). Eugene, Oregon: University of Oregon Press, 1995

14 Ding L, Murphy M B, He Y, et al. Effects of brominated flame retardants and brominated dioxins on steroidogenesis in H295R human adrenocortical carcinoma cell line. Environ Toxicol Chem, 2007, 26: 764-772

15 Press C M L, Evensen $\varnothing$. The morphology of the immune system in teleost fishes. Fish Shellfish Immun, 1999, 9: 309-318

16 Burreau S, Zebühr Y, Broman D, et al. Biomagnification of polychlorinated biphenyls (PCBs) and polybrominated diphenyl ethers (PBDEs) studied in pike (Esox lucius), perch (Perca fluviatilis) and roach (Rutilus rutilus) from the Baltic Sea. Chemosphere, 2004, 55: 1043-1052

17 Shao J, Dabrowski M J, White C C, et al. Flow cytometric analysis of BDE 47 mediated injury to rainbow trout gill epithelial cells. Aquat Toxicol, 2010, 97: 42-50

18 Holm G, Norrgren L, Andersson T, et al. Effects of exposure to food contaminated with PBDE, PCN or PCB on reproduction, liver morphology and cytochrome P450 activity in the three-spined stickleback, Gasterosteus aculeatus. Aquat Toxicol, 1993, 27: 33-55

19 Kuiper R V, Van den Brandho E J, Leonards P E G, et al. Toxicity of tetrabromobisphenol A (TBBPA) in zebrafish (Danio rerio) in a partial life-cycle test. Arch Toxicol, 2007, 81: 1-9

20 Bainy A C D, Saito E, Carvalho P S M, et al. Oxidative stress in gill, erythrocytes, liver and kidney of Nile tilapia (Oreochromis niloticus) from a polluted site. Aquat Toxicol, 1996, 34: 151-162

21 Alvarez R M, Morales A E, Sanz A. Antioxidant defenses in fish: Biotic and abiotic factors. Rev Fish Biol Fisher, 2005, 15: 75-88

22 Key P B, Hoguet J, Chung K W, et al. Lethal and sublethal effects of simvastatin, irgarol, and PBDE-47 on the estuarine fish, fundulus heteroclitus. J Environ Sci Health B-Pestic, 2009, 44: 379-382
23 de Wit C A. An overview of brominated flame retardants in the environment. Chemosphere, 2002, 46: 583-624

24 Juliette L. New insights into the endocrine disrupting effects of brominated flame retardants. Chemosphere, 2008, 73: 216-222

25 Hahn M E. The aryl hydrocarbon receptor: A comparative perspective. Comp Biochem Physiol C Toxicol Parmacol, 1998, 121: 23-53

26 Carney S A, Peterson R E, Heideman W. 2,3,7,8-Tetrachlorodibenzop-dioxin activation of the aryl hydrocarbon receptor/aryl hydrocarbon receptor nuclear translocator pathway causes developmental toxicity through a CYP1A-independent mechanism in zebrafish. Mol Pharmacol, 2004, 66: 512-521

27 Brown D J, Van Overmeire I, Goeyens L, et al. Analysis of Ah receptor pathway activation by brominated flame retardants. Chemosphere, 2004, 55: 1509-1518

28 Legler J, Brouwer A. Are brominated flame retardants endocrine disruptors? Environ Int, 2003, 29: 879-885

29 Schriks M, Zvinavashe E, David F J, et al. Disruption of thyroid hormone-mediated Xenopus laevis tadpole tail tip regression by hexabromocyclododecane (HBCD) and 2, 2', 3, 3', 4, 4', 5, 5', 6-nona brominated diphenyl ether (BDE206). Chemosphere, 2006, 65: 19041908

30 De Wit M, Keil D, Remmerie N, et al. Molecular targets of TBBPA in zebrafish analysed through integration of genomic and proteomic approaches. Chemosphere, 2008, 74: 96-105

31 Guellec L K, Lawless K, Valotaire Y, et al. Vitellogenin gene expression in male rainbow trout(salmo gairdnerl). Gen Comp Endocrinol, 1988, 71: 359-371

32 Brion F, Tyler C, Palazzi R X, et al. Impacts of 17 [beta]-estradiol, including environmentally relevant concentrations, on reproduction after exposure during embryo-larval-, juvenile- and adult-life stages in zebrafish (Danio rerio). Aquat Toxicol, 2004, 68: 193-217

Open Access This article is distributed under the terms of the Creative Commons Attribution License which permits any use, distribution, and reproduction in any medium, provided the original author(s) and source are credited. 